cathode spot, giving rise to gas velocities of the order of $10^{4}$ to $10^{5} \mathrm{~cm}$. per sec.

Dr. G. R. Salter, of the Department of Industrial Metallurgy, contributed a paper which described the results of an investigation of the absorption of oxygen by titanium melted by an electric arc in an atmosphere of argon containing controlled quantities of oxygen. The effect of time, oxygen partial pressure, arc length, current, electrode composition and gas flow conditions had been determined. The interpretation of the results led to the conclusion that in this system the rate-controlling process was the diffusion of oxygen across a 'stagnant' boundary-layer of gas of the order of $10^{-3} \mathrm{~cm}$. thickness, adjacent to the molten metal, which took place over a high temperature active area where the oxygen was dissociated. The magnitude of the active area was determined by the current and are length, and the thickness of the boundary layer by the velocity of the cathode plasma-jet which impinged on the anode.

Mr. J. B. Wilkinson, also of the Department of Industrial Metallurgy, gave an account of work on heat transfer in which energy balances had been determined for arcs operating between a tungsten cathode and a water-cooled copper anode in atmospheres of argon, nitrogen, helium and hydrogen. The existence of plasma-jets in these arcs had been demonstrated, their velocities estimated and attempts made to separate the heat transfer from the plasmajet from that due to electron heating of the anode. The interpretation of the measurements of the heat transferred from the plasma-jet was along similar lines to that proposed by Salter for mass transfer, that is to say, with convection transferring the heat to a boundary-layer adjacent to the metal surface. Some success had been achieved by the application of a conventional non-dimensional treatment of convective heat transfer with the plasma-jet replaced by an equivalent source of hot gas emerging from a tube.

In addition to their role in heat and mass transfer, plasma-jets are also responsible for the transfer of metal droplets from the molten wire electrode to the weld plate. This was shown by Mr. J. C. Needham, who described work carried out at the Electrical Research Association in which a study had been made of the detachment and flight of aluminium droplets by high-speed colour photography $(8,000$ frames per sec.). The existence and effect of the plasma-jet could be inferred from a stream of metal vapour emanating from the droplets flowing in the direction of the jet and from the fact that the velocity of the drops continued to increase, with accelerations of $10 g$ to $100 \mathrm{~g}$, after they had been detached from the electrode wire, attaining terminal velocities in excess of $500 \mathrm{~cm} . / \mathrm{sec}$. Experimental determinations of the droplet velocity as a function of current, derived from the photographs taken by Needham, and from trajectory determinations by Mr. C. J. Cooksey of the University of Birmingham, compared well with theoretical calculations based on a model in which the drop became detached when the force exerted on it by the plasma-jet exceeded the restraining force of surface tension, and was then freely accelerated across the are by the impinging gas stream.

An interesting characteristic of the electric arc is that if it is intensively cooled, for example, by operating it through a narrow cooled orifice, then the core temperature is increased. This is because the con. ducting area contracts, so that which remains must have a higher degree of ionization and hence a higher temperature in order to maintain the required eurrent. Spectroscopists and arc physicists have utilized this property of the are to heat gas to temperatures up to $50,000^{\circ} \mathrm{C}$. for the measurement of collision cross-sections and the transition probabilities of ionized and excited atoms and for fundamental magnetohydrodynamic studies. Mr. A. R. Moss, of the Ministry of Supply, elaborated on the behaviour of the constricted arc and showed how it could be harnessed to technological advantage. $\mathrm{He}$ described the various types of plasma-jet projectors and constricted arc torches developed in the Armament Research and Development Establishment, with emphasis on the design and characteristics of devices operating with a power consumption up to $100 \mathrm{kV}$. amp., although much more powerful equipments were mentioned. Their many potential technological applications include the melting, cutting and spraying of metallic and non-metallic materials in noncontaminating atmospheres, chemical synthesis and the production of high-temperature gas streams at hypersonic velocities. $\quad$ D. R. MILNER

\title{
INTERNATIONAL CONGRESS ON ACOUSTICS
}

$\mathrm{T}$ HE third International Congress on Acoustics was held in Stuttgart during September 1--8 under the presidency of Prof. Erwin Meyer.

The first of the series was held in Delft in 1953 and the second in Cambridge, Massachusetts, in 1956. Already the number of participants has risen from the original 600 to more than 1,000, and in the recent congress necessitated the individual papers being read in eight concurrent sessions. The mornings were devoted to review lectures, which all could attend. These, and the papers presented, covered architectural acousties, ultrasonic techniques and their applications to the study of molecular physics, acoustical properties of materials employed in industry, noise and its abatement (in particular aircraft noise), physiological and psychological acoustics.
If one tries to assess the progress made since the last congress and which is likely to continue in the future, one would perhaps select the last two of these as of most interest. The two reviews given on the subject of the noise of jets and the quantity of smaller papers which followed illustrated the strides which have been made since the last congress, where the subject of aeronauties interested but a few speakers. The increasing noise-level to which we are subjected has stimulated more research into the functioning of the ear and the human processes of sound perception, which also brought out a stimulating array of papers.

In building acoustics and molecular acoustics one has the feeling that the peak of development has passed. In the former subject it seems now to be a 
question of fine adjustments to existing knowledge, while in the latter new developments may only be expected by going to extreme temperatures and pressures with adaptations of existing techniques. To illustrate the importance of noise in daily life and methods of measuring it, the regional authorities of Baden-Würtemburg opened to the public an exhibit in a Stuttgart Museum entitled "Weniger Lärm".

It was announced that the next international congress would be held in Copenhagen in 1962, and if the number of participants should continue to increase at the present rate this will involve the local organiza. tion in much hard thinking about how they are to lodge them and deal with the reading of the many papers expected.

This situation is not peculiar to acousties, but there is a possibility of splitting the auditory into roughly equal numbers of those concerned with physical and physiological acoustics and those interested mainly in architectural, musical and industrial applications. Perhaps two congresses en suite with a week-end of social activities and excursions sandwiched between them might overcome some of the difficulties of organization.

The proceedings of the congress are to be published in book form by Elsevier Press. E. G. Richardson

\section{PHOTOGRAPHY IN THE INTERNATIONAL GEOPHYSICAL YEAR}

A SYMPOSIUM on photography in the International Geophysical Year was held in Edinburgh on June 6, under the auspices of the Scientific and Technical Group of the Royal Photographic Society of Great Britain.

Following his address of welcome on behalf of the University of Edinburgh, Sir Edward Appleton stated that he believed the effect of the International Geophysical Year on association between geophysicists would be a permanent one, and recalled the descent of the recent great collaboration from earlier International Polar Years. He then described some of the ionospheric work carried out during the International Geophysical Year and directed attention to the valuable part played by photography in making possible permanent records. In conclusion, he spoke of the most striking discovery of the Van Allen radiation belt. Miss Harker, president of the Royal Photographic Society, replied and went on to discuss the wide compass of photography, illustrated by the nature of the subject of the symposium.

The study of aurorae by all-sky cameras was described by Dr. G. M. Thomas, of the Balfour Stewart Auroral Laboratory. He pointed out that remoteness and erratic occurrence make auroral data scanty, and that any casual collection of data is bad statistically. However, full-time observation is a costly matter, but sky cameras could provide the necessary supplement to visual observation. A system was described consisting of a motion picture camera viewing a large convex mirror, the mirror being heated to keep off frost and snow, and a calendar and watch placed in the field of view. Timing of the camera's function was provided by a synchronous motor. A film illustrating the systematic motion of the aurorae was shown. It is of great importance to correlate the sudden alterations which occur with changes in the magnetic field at the ground.

The next contribution reviewed some of the contributions of photographic techniques to rocket and satellite work, and deseribed particularly the ballistic cameras developed at University College, London, for the 'grenade' experiment. This is a method of finding upper-air winds and temperatures by measuring the time of travel of sound from grenades fired from an ascending rocket. The special function of photography here is to locate the grenade bursts with great precision. When the experiment is carried out in daylight, special techniques are necessary to obtain rapid triggering of the shutters by light from the grenades. Experiments under preparation for X-ray observation of the Sun and ultra-violet astronomy of the stars were also described. The latter work is being conducted in collaboration with Dr. H. E. Butler, of the Royal Observatory, Edinburgh, who then described his use of a technique, due originally to Dr. Baker, of the same Observatory, to bring up the detail of very faint interstellar absorption lines. Basically, the problem is to bring out the signal from the 'background noise' grain in the plates, and it is accomplished by careful photometering and summing of the results from many plates, together with subtraction from a standard spectrum to remove the emission structure. The results were extremely impressive, as indeed was the amount of work required to obtain them; a million separate readings from twenty-seven different exposures were obtained.

Dr. C. J. Waddington, of the University of Bristol, described his subject as the study of the 'footprints' of cosmic ray particles. Due to the vastness of his subject, he limited his discussion to an extended series of high-altitude balloon flights with nuclear emulsions made with the avowed intention of monitoring the long-term variation of the primary cosmic radiation. Seventy-three balloon flights were made by a group led by Prof. E. P. Ney (Minnesota). A typical payload consisted of a dozen 4 in. $\times 4$ in. $600 \mu$ Ilford G.5 emulsion plates, together with a single counter and an ion chamber. Although protons are more abundant, $\alpha$-particles were chosen for the study for a variety of reasons, among which were the complications of an albedo of protons from disintegrations and the greater ease of finding and counting $\alpha$-particle tracks in nuclear emulsions. The results of these observations are still being analysed, but already it is clear that differences in the variation of $\alpha$-particle and proton flux after a solar flare should ultimately throw light on the properties of the space between us and the Sun.

A paper by Dr. W. I. Arvegwitch, of the U.S.S.R. Academy of Sciences Institute of Geography, was read for him in his absence. His paper discussed photo-topographic methods used by his Institute for the study of glaciers. For more than a decade glaciation has been studied by aerial photography although stereo-photogrammetric surveys from the 